УДК 630*524.634: 630*561.26: 519.876

\title{
ФАКТОРНЫЙ АНАЛИЗ КОЛЕБАТЕЛЬНЫХ ВОЗМУЩЕНИЙ ДЕНДРОРЯДОВ РАЗНОВОЗРАСТНОГО СОСНЯКА СИБИРИ ПО КРИВЫМ ВЫСОТ
}

(C) 2015

П.М. Мазуркин, доктор технических наук, профессор, заведующий кафедрой природообустройства,

академик РАЕ и РАЕН, член Европейской Академии Естествознания ФГБОУ «Поволжский государственный технологический университет», Йошкар-Ола (Россия), kaf_po@mail.ru

Введение. Колебательное возмущение является основой поведения Вселенной [2], а значит и Земли и растительных сообществ на ней. Деревья возникли более 300 млн. лет назад [1] и за время эволюции приобрели уникальные способности колебательной адаптации.

Наши исследования показали, что геостатистика пробных площадей сосны $[3,5]$ подчиняется общим географическим и экологическим закономерностям [4]. При этом выдела сосняков и березняков даже на локальной территории имеют четкие биотехнические закономерности распределения по площади и другим параметрам [11]. Территориальное [16] и компонентное $[9,12]$ равновесие достигается симбиотическим развитием и ростом отдельных дендронов и их популяций. При этом сухостойные сосны органично вплетены в функциональный каркас поведения древостоя [6].

Это было доказано факторным анализом $[6-8,13,20]$ таксационных показателей сосняков и ельников. Замечено, что обобщенной волновой функции в виде асимметричного вейвлет-сигнала подчиняются не только деревья и их сообщества (биогруппы, древостои, массивы), но и веточки $[17,19]$ и даже хвоинки на отдельной веточке [18].

Например [20], материнская ель закономерно «высаживает» и управляет развитием и ростом своего подроста и дочерних особей по волновой функции биоэнергетического воздействия, причем в зависимости от азимута расположения отпрысков.

Для формирования теории общей фитоценологии новым является то, что одна и та же конструкция волновой функции соблюдается в жизнедеятельности растений в луговом [14], лесолуговом [15] и лесном [12, 20] фитоценозах. Даже контур лесной поляны оказывает геоэкологическое влияние на жизнедеятельность деревьев [13].

При этом ретроспективу поведения отдельного учетного дерева можно измерять по годичным слоям на отрезках керна [10], что позволило получить нам десятки патентов на изобретения для дендроэкологического мониторинга территории с растущими деревьями.

Цель статьи - в продолжение [6] показать методику факторного анализа волновыми уравнениями 11 параметров (табл. 1) кривых высот у дендрорядов растущих (дендроны до валки модельных деревьев) и сухостойных (ксилоны) ангарских сосен. 
Таблица 1 Структурные параметры дендрорядов сосняка на пробной площади по кривым высот

\begin{tabular}{|c|c|c|c|c|c|c|c|c|r|r|c|}
\hline Дендрометрический & \multirow{2}{*}{$\begin{array}{c}\text { рлтд сосен } \\
\text { рят. }\end{array}$} & \multicolumn{3}{|c|}{ Параметры толщины, см } & \multicolumn{5}{|c|}{ Параметры высоты, м } \\
\hline сверхлидеры & 6 & 25.8 & 66.2 & 40.4 & 42.97 & 166 & 27.4 & 32.5 & 5.1 & 29.62 & 38.1 \\
\hline сильнейшие & 4 & 22.2 & 52.6 & 30.4 & 34.25 & 67 & 23.3 & 30.5 & 7.2 & 26.75 & 31.0 \\
\hline очень сильные & 4 & 25.4 & 56.0 & 30.6 & 37.10 & 68 & 24.2 & 30.0 & 5.8 & 26.88 & 30.3 \\
\hline сильные & 6 & 19.8 & 43.6 & 23.8 & 30.00 & 82 & 20.3 & 28.3 & 8.0 & 24.23 & 31.3 \\
\hline слабонапряженные & 9 & 10.4 & 71.4 & 61.0 & 28.67 & 62 & 12.1 & 29.0 & 16.9 & 20.50 & 29.1 \\
\hline малонапряженные & 16 & 12.2 & 68.2 & 56.0 & 37.50 & 55 & 10.5 & 28.7 & 18.2 & 22.21 & 28.4 \\
\hline напряженные & 9 & 23.4 & 68.6 & 45.2 & 39.89 & 62 & 22.0 & 27.8 & 5.8 & 25.28 & 27.8 \\
\hline сильнонапряженные & 16 & 19.8 & 68.2 & 48.4 & 37.97 & 66 & 19.5 & 27.6 & 8.1 & 24.74 & 27.8 \\
\hline высокоинтенсивные & 22 & 13.4 & 63.6 & 50.2 & 24.73 & 52 & 12.0 & 27.0 & 15.0 & 18.66 & 27.0 \\
\hline супернапряженные & 14 & 22.8 & 41.6 & 18.8 & 31.36 & 329 & 20.0 & 25.2 & 5.2 & 22.53 & 35.9 \\
\hline начало ослабления & 21 & 19.0 & 64.0 & 45.0 & 32.99 & 100 & 17.2 & 26.8 & 9.6 & 21.81 & 28.0 \\
\hline сопротивляющиеся & 20 & 14.8 & 60.6 & 45.8 & 31.82 & 69 & 13.0 & 26.5 & 13.5 & 19.63 & 26.6 \\
\hline слабеющие & 10 & 14.8 & 38.6 & 23.8 & 26.29 & 387 & 12.4 & 23.5 & 11.1 & 18.30 & 44.2 \\
\hline слабоватые & 28 & 18.0 & 56.6 & 38.6 & 42.08 & 553 & 13.8 & 26.0 & 12.2 & 22.33 & 44.6 \\
\hline слабые деревья & 9 & 16.4 & 61.2 & 44.8 & 39.18 & 2500 & 12.6 & 26.0 & 13.4 & 19.78 & 198.2 \\
\hline очень слабые & 4 & 19.8 & 62.8 & 43.0 & 48.60 & 2185 & 13.0 & 24.6 & 11.6 & 21.15 & 178.7 \\
\hline аутсайдеры & 5 & 31.6 & 66.8 & 35.2 & 46.22 & 63 & 15.4 & 21.9 & 6.5 & 18.56 & 21.4 \\
\hline усохшие сосны & 16 & 7.2 & 53.8 & 46.6 & 29.93 & 73 & 10.5 & 28.5 & 18.0 & 20.25 & 28.6 \\
\hline
\end{tabular}

Все 11 показателей образуют множество, характеризующее изучаемую систему в виде пробной площади сосняка. Каждый дендроряд содержит $N$ сосен. Границы кривых высот в дендрорядах даются минимальными $D_{\min }, H_{\min }$ и максимальными $D_{\max }, H_{\max }$ диаметрами и высотами. Размах между фактическими толщинами $\Delta D=D_{\max }-D_{\min }$ и высотами $\Delta H=H_{\max }-H_{\min }$ определяет результат поведения сосняка Сибири за время жизни старой сосны в 464 года $[7,8]$. По известной в классической статистике доктрине среднего дерева для сравнения учли среднеарифметические значения $\bar{D}$ и $\bar{H}$. По дендрорядам вычисляли оптимальные значения $D^{*}$ и $H^{*}$.

Вейвлет (всплеск) - это математическая функиия. Английское слово «wavelet» означает в переводе «маленькая волна». Вейвлеть - это семейство функиий, «волны, идущие друг за другом». Вейвлет имеет четкую амплитудночастотную характеристику и поэтому может изучаться методами классической механики колебаний.

При этом любой гармоничный вейвлет асимметричной формы имеет вид

$$
\begin{gathered}
y=\sum_{i=1}^{m} y_{i}, y_{i}=A_{i} \cos \left(\pi x / p_{i}-a_{8 i}\right), \\
A_{i}=a_{1 i} x^{a_{2 i}} \exp \left(-a_{3 i} x^{a_{4 i}}\right), p_{i}=a_{5 i}+a_{6 i} x^{a_{7 i}},
\end{gathered}
$$

где $y$ - показатель, $i$ - номер составляющей показателя, $m$ - количество членов модели (1), $x$ - объясняющая переменная (влияющий фактор), $A$ - амплитуда (половина) вейвлета (ось $y$ ), $p$ - полупериод колебания (ось $x$ ), $a_{1} \ldots a_{8}$ - параметры модели (1). 
Физико-математический подход (табл. 2) предполагает понимание рядов из таблицы 1 как множества отражений сложного процесса поведения сосняка.

Таблица 2

Полный факторный анализ волновыми закономерностями и рейтинг факторов

\begin{tabular}{|l|c|c|c|c|c|c|c|c|c|c|c|c|c|}
\hline \multirow{2}{*}{$\begin{array}{c}\text { Влияющие } \\
\text { факторы } x\end{array}$} & \multicolumn{7}{|c|}{ Сависимые факторы (показатели $y$ ) } & Место \\
\cline { 2 - 10 } & $N$ & $D_{\min }$ & $D_{\max }$ & $\Delta D$ & $\bar{D}$ & $D^{*}$ & $H_{\min }$ & $H_{\max }$ & $\Delta H$ & $\bar{H}$ & $H^{*}$ & $\Sigma r$ & $I_{x}$ \\
\hline Число $N$ & 0,9982 & 0,7540 & 0,7940 & 0,8748 & 0,7480 & 0,4734 & 0,6640 & 0,7800 & 0,4993 & 0,7527 & 0,4696 & 7,8080 & 11 \\
\hline Диаметр $D_{\min }$ & 0,5333 & 0,9996 & 0,6870 & 0,8551 & 0,7515 & 0,7826 & 0,9345 & 0,8974 & 0,9787 & 0,9460 & 0,6088 & 8,9745 & 10 \\
\hline Диаметр $D_{\max }$ & 0,9619 & 0,8274 & 0,9988 & 0,9397 & 0,8751 & 0,8090 & 0,7727 & 0,7938 & 0,8198 & 0,8488 & 0,9910 & 9,6380 & 7 \\
\hline Размах $\Delta D$ & 0,9192 & 0,9173 & 0,9688 & 0,9992 & 0,9678 & 0,8045 & 0,9080 & 0,9181 & 0,8940 & 0,8759 & 0,9585 & 10,1313 & 2 \\
\hline Средний $\bar{D}$ & 0,9123 & 0,8417 & 0,9642 & 0,8450 & 0,9992 & 0,8150 & 0,7931 & 0,9466 & 0,6803 & 0,8954 & 0,9450 & 9,6378 & 8 \\
\hline Оптимум $D^{*}$ & 0,9521 & 0,8864 & 0,9557 & 0,8076 & 0,7796 & 1,0000 & 0,8628 & 0,7193 & 0,8284 & 0,7911 & 0,9996 & 9,5826 & 9 \\
\hline Высота $H_{\min }$ & 0,8746 & 0,9652 & 0,9048 & 0,9277 & 0,8315 & 0,7684 & 0,9982 & 0,9609 & 0,9829 & 0,9846 & 0,8578 & 10,0566 & 4 \\
\hline Высота $H_{\max }$ & 0,7546 & 0,9294 & 0,8689 & 0,9273 & 0,9479 & 0,8834 & 0,9695 & 0,9989 & 0,9613 & 0,9683 & 0,8492 & 10,0587 & 3 \\
\hline Размах $\Delta H$ & 0,9502 & 0,9857 & 0,9102 & 0,9346 & 0,8914 & 1,0000 & 0,9937 & 0,9875 & 0,9989 & 0,9553 & 0,9997 & 10,6072 & 1 \\
\hline Средняя $\bar{H}$ & 0,9631 & 0,9576 & 0,7017 & 0,9180 & 0,9079 & 0,7732 & 0,9637 & 0,9476 & 0,8932 & 0,9995 & 0,8247 & 9,8502 & 5 \\
\hline Оптимум $H^{*}$ & 0,9312 & 0,8844 & 0,9432 & 0,9665 & 0,4174 & 0,99999 & 0,8062 & 0,9855 & 0,9466 & 0,9663 & 0,9995 & 9,8467 & 6 \\
\hline Сумма $\Sigma r$ & 9,7507 & 9,9487 & 9,6973 & 9,9955 & 9,1173 & 9,1094 & 9,6664 & 9,9356 & 9,4834 & 9,9839 & 9,5034 & 106,192 & - \\
\hline Место $I_{y}$ & 5 & 3 & 6 & 1 & 10 & 11 & 7 & 4 & 9 & 2 & 8 & - & 0,8776 \\
\hline
\end{tabular}

Примечание. Здесь $r$ - коэффициент корреляции тренда или не волновых закономерностей.

Коэффициент коррелятивной вариации для всего множества из 11 факторов равен $106,192 / 11^{2}=0,8776$. Этот системный показатель по сравнению с трендами в $0,8776 / 0,4918=1,784$ раза больше. Поэтому волновая теория разновозрастного сосняка с пятью поколениями доказана. Как влияющая переменная на первом месте находится размах $\Delta H$ высоты ствола, на втором - размах $\Delta D$ толщины и на третьем - максимальная высота $H_{\max }$. В таблице 2 как зависимый показатель на первом месте - размах $\Delta D$ толщины, на втором - средняя высота $\bar{H}$ сосен и на третьем - минимальный диаметр $D_{\min }$. Ранговые распределения значений факторов показывают высокую добротность исходных для моделирования данных с коэффициентами корреляции от 0,99 до 1,00.

Сильные бинарные отношения между факторами показаны в таблице 3.

Таблица 3

Корреляционная матрица сильных колебательных бинарных связей при $r \geq 0,7$

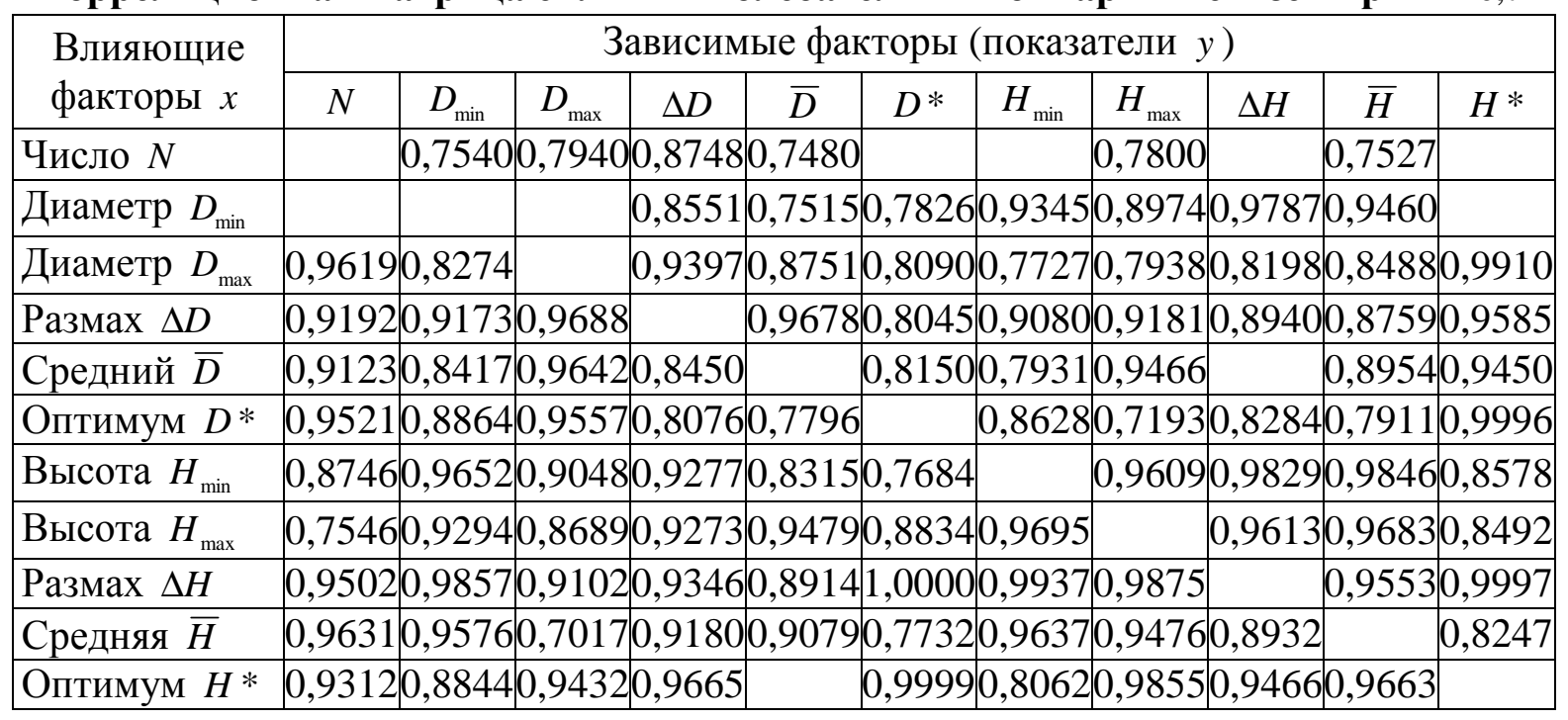


Влияние требований к уровню адекватности модели (1) можно оценить, если значения коэффициента корреляции бинарных отношений (по таблице 2) распределить по интервальной шкале. Результат приведен в таблице 4.

Таблица 4

Динамика бинарных связей параметров сосняка

Допустимый Количество Количество Количество коэффициент формул $N_{(1)}$ оставшихся оставшихся корреляции

\begin{tabular}{|c|c|c|c|}
\hline$r]$ & отношений & в матрице & матрицы \\
\hline 0 & 110 & 11 & 11 \\
\hline 0.1 & 110 & 11 & 11 \\
\hline 0.2 & 110 & 11 & 11 \\
\hline 0.3 & 110 & 11 & 11 \\
\hline 0.4 & 110 & 11 & 11 \\
\hline 0.5 & 107 & 11 & 11 \\
\hline 0.6 & 105 & 11 & 11 \\
\hline 0.7 & 102 & 11 & 11 \\
\hline 0.8 & 83 & 11 & 11 \\
\hline 0.9 & 54 & 10 & 11 \\
\hline 0.95 & 31 & 10 & 11 \\
\hline 0.96 & 25 & 10 & 11 \\
\hline 0.97 & 12 & 6 & 7 \\
\hline 0.98 & 11 & 5 & 7 \\
\hline 0.99 & 6 & 4 & 3 \\
\hline 1 & 1 & 1 & 1 \\
\hline
\end{tabular}

Допустимый коэффициент $[r]$ показывает правую границу интервалов шкалы. Задаваясь $[r]$, можно оценить уровень функциональной связности изучаемой системы.

Нулевой коэффициент корреляции образуется при вычислении средней арифметической величины.

Таблица 4 отображает также динамику требований к адекватности проведенных измерений.

После идентификации тренда получены следующие формулы:

- количества формул (рис. 1a) корреляционной матрицы

$$
N_{(1)}=110-111,88848[r]^{6,46861} \text {; }
$$

- количество строк в корреляционной матрице (рис. 1б)

$$
N_{\leftrightarrow}=11-10,19924[r]^{33,73730} ;
$$

- количество столбцов в корреляционной матрице (рис. 1в)

$$
N_{\uparrow}=11-10,65501[r]^{45,37917} .
$$

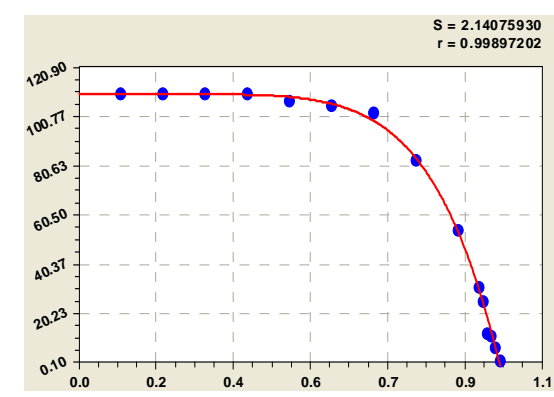

a) количество формул

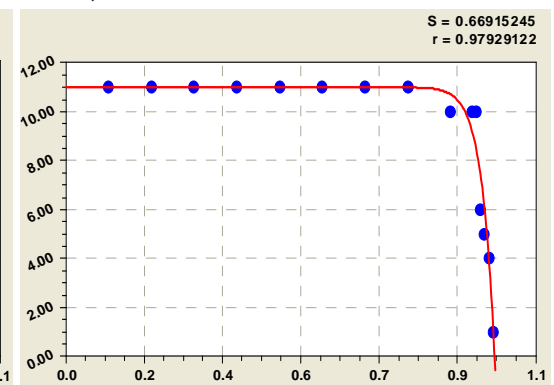

б) количество строк матрицы

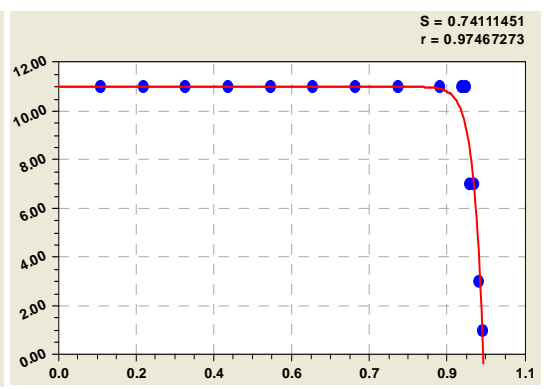

в) количество столбцов

Рис. 1. Характеристика функциональной связности параметров у 18 дендрорядов сосняка в зависимости от уровня требований к адекватности по коэффициенту корреляции

Из графиков видно, что наиболее устойчивым является количество столбцов или показателей, когда по данным таблицы 4 вплоть до уровня адекватности 0,96 сохраняется 11 зависимых факторов. Этот уровень по строкам завершается на уровне 0,8 . Численность бинаров снижается с коэффициента 0,5.

Далее рассмотрим сверхсильные бинарные связи (табл. 5).

Все три оставшихся показателя зависят от размаха высоты ствола. Этот факт еще раз доказывает преимущества английской системы лесной таксации, когда выдел леса или древостой характеризуются и оцениваются по результатам измерений не менее 100 лидирующих в росте в высоту деревьев. 
Таблица 5

Бинарные связи при $r \geq 0,99$

\begin{tabular}{|l|c|c|c|}
\hline \multirow{2}{*}{$\begin{array}{l}\text { Влияющие } \\
\text { факторы } x\end{array}$} & \multicolumn{3}{|c|}{ Показатели $y$} \\
\cline { 2 - 4 } & $D^{*}$ & $H_{\min }$ & $H^{*}$ \\
\hline Диаметр $D_{\max }$ & & & 0,9910 \\
\hline Оптимум $D^{*}$ & & & 0,9996 \\
\hline Размах $\Delta H$ & 1,0000 & 0,9937 & 0,9997 \\
\hline $\begin{array}{l}\text { Оптимум } \\
H^{*}\end{array}$ & 0,9999 & & \\
\hline
\end{tabular}

Для компактной записи уравнения применяется матричная форма (табл. 6).

На рисунке 2 даны графики закономерностей $D^{*}=f(\Delta H)$ и $H^{*}=f(\Delta H)$.

Изменение предельно возможного диаметра происходит на двух интервалах изменения размаха высоты сосен: а) при $\Delta H=4,6-6,4$ м; б) в интервале $\Delta H=10-15$ м, когда напряженность роста в толщину наиболее высокая и динамичная. Аналогичные интервалы размаха наблюдаются и у функции $H^{*}=f(\Delta H)$, но первый промежуток размаха характерен плавным (апериодическим) изменением теоретически возможной высоты ствола ангарских сосен.

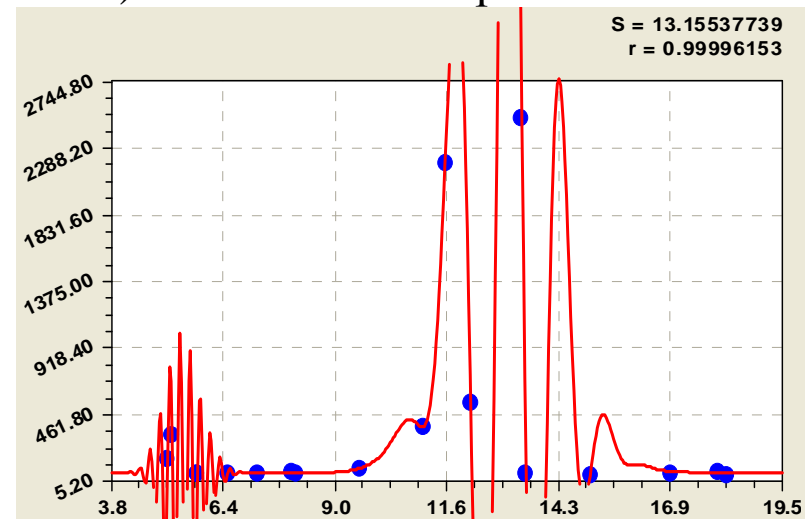

Оптимум толщины

(предельный диаметр) ствола

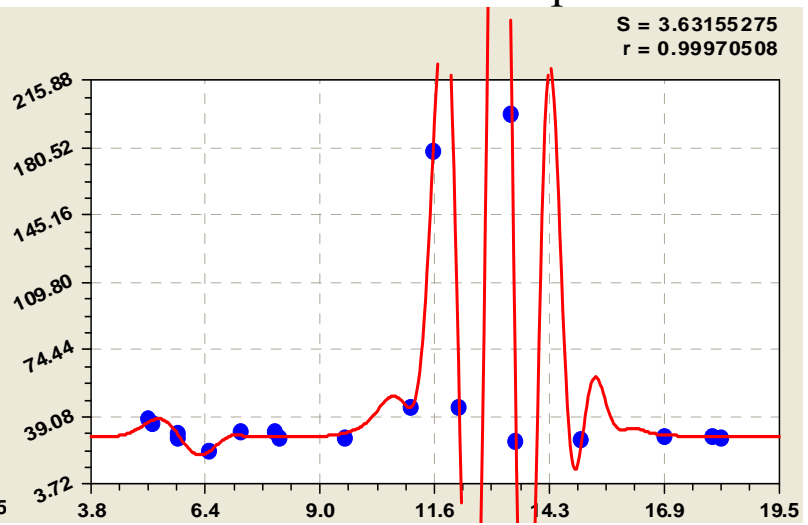

Оптимум высоты

(теоретический предел) ствола

Рис. 2. Влияние размаха высоты ствола на изменение оптимумов кривых высот

Таблица 6

Параметры волны (1) сверхсильных бинарных связей у 18 дендрорядов из 219 сосен

\begin{tabular}{|c|c|c|c|c|c|c|c|c|c|}
\hline \multirow{2}{*}{$\begin{array}{c}№ \\
i\end{array}$} & \multicolumn{4}{|c|}{ Амплитуда колебания } & \multicolumn{4}{|c|}{ Полупериод и сдвиг колебания } & \multirow{2}{*}{$\begin{array}{l}\text { Коэфф. } \\
\text { коррел. }\end{array}$} \\
\hline & $a_{1 i}$ & $a_{2 i}$ & $a_{3 i}$ & $a_{4 i}$ & $a_{5 i}$ & $a_{6 i}$ & $a_{7 i}$ & $a_{8 i}$ & \\
\hline \multicolumn{10}{|c|}{ Влияние размаха $\Delta H$ высоты на изменение оптимума $D^{*}$ толщины ствола } \\
\hline 1 & 7,48841e-73 & 112,53233 & 8,85236 & 1 & 0 & 0 & 0 & 0 & \multirow{4}{*}{1,0000} \\
\hline 2 & 66,42304 & 0 & 0 & 0 & 0 & 0 & 0 & 0 & \\
\hline 3 & $2,68572 \mathrm{e}-136$ & 181,77450 & 5,91480 & 1,24860 & 1,56117 & $-0,042927$ & 1 & $-2,67630$ & \\
\hline 4 & $1,79141 \mathrm{e}-50$ & 175,77314 & 32,40034 & 1 & 0,11758 & 0 & 0 & $-0,53643$ & \\
\hline \multicolumn{10}{|c|}{ Влияние оптимума $H^{*}$ высоты на изменение оптимума $D^{*}$ толщины ствола } \\
\hline 1 & 27,87414 & 1,18057 & 0 & 0 & 0 & 0 & 0 & 0 & \multirow{3}{*}{0,9999} \\
\hline 2 & 44,43730 & 1,01799 & $-0,012587$ & 1 & $-4,05944$ & 1,72040 & 0,59846 & 0,94800 & \\
\hline 3 & $6,08316 \mathrm{e}-133$ & 116,22900 & 2,94192 & 1 & 1,52391 & 0,0093984 & 1 & 5,31422 & \\
\hline \multicolumn{10}{|c|}{ Влияние размаха $\Delta H$ высоты на изменение оптимума $H^{*}$ высоты ствола } \\
\hline 1 & $3,83750 \mathrm{e}-72$ & 109,4250 & 8,57395 & 1 & 0 & 0 & 0 & 0 & \multirow{4}{*}{0,9997} \\
\hline 2 & 28,68158 & 0 & 0 & 0 & 0 & 0 & 0 & 0 & \\
\hline 3 & $3,37753 \mathrm{e}-136$ & 185,43364 & 7,73556 & 1,17552 & 1,45743 & $-0,018635$ & 1,24171 & $-2,83668$ & \\
\hline 4 & $1,68707 \mathrm{e}-35$ & 111,84071 & 19,67185 & 0,99751 & 16,80340 & $-1,90150$ & 1,01023 & $-4,56944$ & \\
\hline \multicolumn{10}{|c|}{ Влияние оптимума $D^{*}$ толщины на изменение оптимума $H^{*}$ высоты ствола } \\
\hline 1 & 2556,8028 & 0 & 4,69083 & 0,0026040 & 0 & 0 & 0 & 0 & \multirow{4}{*}{0,9996} \\
\hline 2 & 0,035418 & 1,18126 & 0 & 0 & 0 & 0 & 0 & 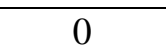 & \\
\hline 3 & $\begin{array}{c}-6,43165 e- \\
30\end{array}$ & 13,00436 & 0,013661 & 1,00287 & 77,75743 & 0,018487 & 0,75681 & 1,33638 & \\
\hline 4 & $-2,72714$ & 0 & $-0,0020144$ & 1 & 3,72288 & 0 & 0 & 3,68195 & \\
\hline
\end{tabular}




\begin{tabular}{|c|c|c|c|c|c|c|c|c|c|}
\hline \multirow{2}{*}{\begin{tabular}{|c|} 
№ \\
$i$ \\
\end{tabular}} & \multicolumn{4}{|c|}{ Амплитуда колебания } & \multicolumn{4}{|c|}{ Полупериод и сдвиг колебания } & \multirow{2}{*}{$\begin{array}{l}\text { Коэфф. } \\
\text { коррел. }\end{array}$} \\
\hline & $a_{1 i}$ & $a_{2 i}$ & $a_{3 i}$ & $a_{4 i}$ & $a_{5 i}$ & $a_{6 i}$ & $a_{7 i}$ & $a_{8 i}$ & \\
\hline \multicolumn{10}{|c|}{ Влияние размаха $\Delta H$ высоты на изменение минимальной высоты $H_{\min }$ ствола } \\
\hline 1 & 32,65152 & 0 & 0,062907 & 1 & 0 & 0 & 0 & 0 & \multirow{4}{*}{0,9937} \\
\hline 2 & $-1,70699 \mathrm{e}-52$ & 82,45013 & 6,37446 & 1,04124 & 0 & 0 & 0 & 0 & \\
\hline 3 & $8,60693 e-56$ & 119,14781 & 10,63956 & 1,16595 & 1,27323 & $-0,19019$ & 0,14079 & 4,53900 & \\
\hline 4 & $-1012,7399$ & 11,72362 & 4,77309 & 1,00002 & 0,096529 & $-0,00039483$ & 1,00049 & 3,82229 & \\
\hline \multicolumn{10}{|c|}{ Влияние максимального диаметра $D_{\max }$ на изменение оптимума $H^{*}$ высоты ствола } \\
\hline 1 & 7129,2384 & 0 & 0,12979 & 1 & 0 & 0 & 0 & 0 & \multirow{4}{*}{0,9910} \\
\hline 2 & $1,05117 \mathrm{e}-146$ & 112,82035 & 2,04511 & 1 & 0 & 0 & 0 & 0 & \\
\hline 3 & $3,03967 \mathrm{e}-125$ & 79,70628 & 0,037681 & 1,67257 & 0,62917 & 0 & 0 & 4.69277 & \\
\hline 4 & $3,03047 \mathrm{e}-142$ & 99,27284 & 1,21266 & 1,01216 & 88,12411 & $-0,98386$ & 1,02664 & $-3,32373$ & \\
\hline
\end{tabular}

Тогда, по-видимому, напряженность внутри любого сосняка естественного происхождения можно оценить по размаху между минимальной и максимальной высотой ствола с указанием наличия двух интервалов $\Delta H$.

Влияние размаха высоты $\Delta H$ на минимальную высоту $H_{\min }$ дано на рисунке 3 . В начале графика наблюдается сильнейший тремор.

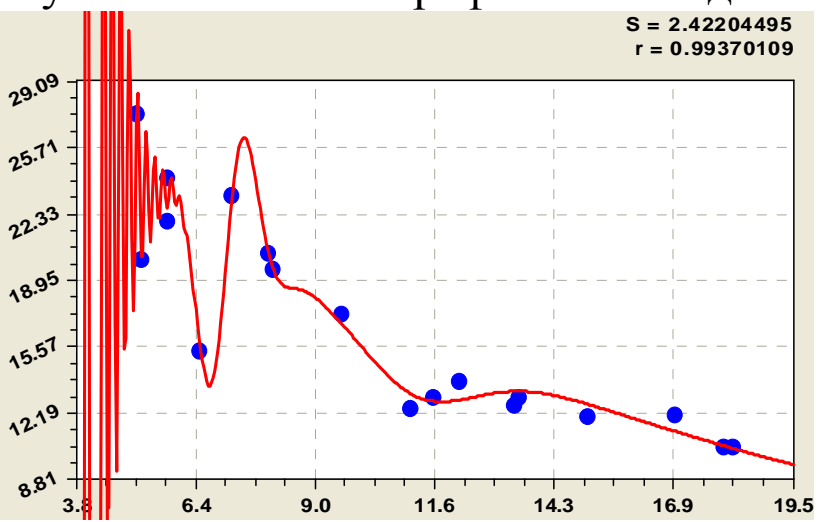

Рис. 3. График функции $H_{\min }=f(\Delta H)$

Сильнейший тремор $H_{\text {min }}$ наблюдается в первом интервале $\Delta H$ от 0 до 5,6 м. Таким образом, сосняку в культурах практически невозможно получить сразу же достаточный размах высоты. Но и на втором промежутке $\Delta H=5,6-8,0$ м происходит сильное однопериодическое колебание. И только с размаха более 8,0 м появляется возможность спокойной дифференциации популяции сосен. Представляет практический интерес тот факт, что в третьем промежутке размаха $\Delta H=10,5-17,0$ м находятся молодые сосны высотой около 12 м. Далее, после $\Delta H>17$ м, располагаются сосенки нового поколения высотой около 10,5 м. При этом известно [7, 8], что новые поколения ангарских сосен появляются только после лесных пожаров.

Максимальный диаметр $D_{\max }$ изменяет (рис. 4) оптимум $H^{*}$ высоты ствола. Запишем уравнение $H^{*}=f\left(D_{\max }\right)$ с параметрами из таблицы 6 в виде

$$
H^{*}=H_{1}^{*}+H_{2}^{*}+H_{3}^{*}+H_{4}^{*},
$$

$$
\begin{aligned}
& H_{1}^{*}=7129,2384 \exp \left(-0,12979 D_{\max }\right), \\
& H_{2}^{*}=1,05117 \cdot 10^{-146} D_{\max } 112,82035 \exp \left(-2,04511 D_{\max }\right), \\
& H_{3}^{*}=A_{1} \cos \left(\pi D_{\max } / p_{1}-4,69277\right), \\
& A_{1}=3,03967 \cdot 10^{-125} D_{\max }^{79,70628} \exp \left(-0,037681 D_{\max }^{1,67257}\right), \\
& p_{1}=0,62917, H_{4}^{*}=A_{2} \cos \left(\pi D_{\max } / p_{2}+3,32373\right), \\
& A_{2}=3,43047 \cdot 10^{-142} D_{\max ^{99,27284}} \exp \left(-1,21266 D_{\max }^{1,01216}\right), \\
& p_{2}=88,12411-0,98386 D_{\max ^{1,02664}} .
\end{aligned}
$$


Первая составляющая модели (5) показывает экспоненциальный спад предельной высоты сосен с увеличением максимального диаметра особей в дендрорядах. При условии $D_{\max } \rightarrow 0$, то есть в семени, теоретически высота будущей сосны может достигнуть 7129 м. Но условия произрастания не дают в полной мере проявиться генетически заложенных пределов. На Земле два

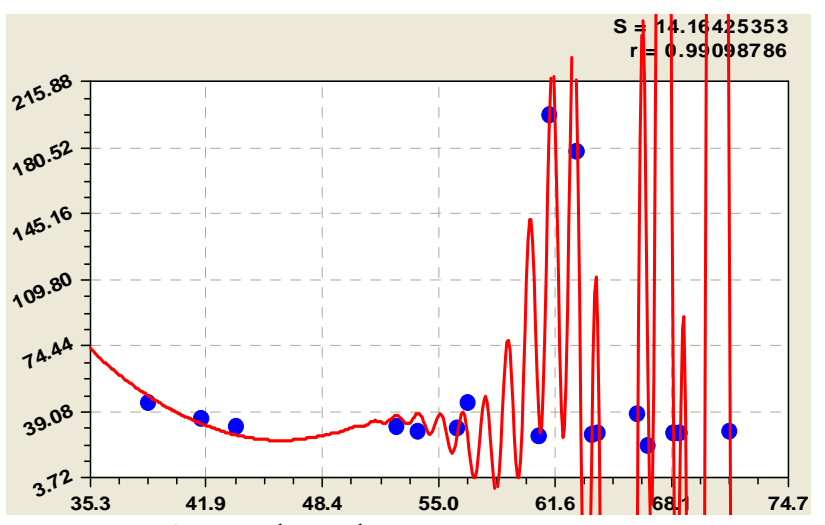

Рис. 4. График функции $H^{*}=f\left(D_{\max }\right)$ века назад были известны деревья высотой более 145 м, а ныне имеются секвойи высотой до 100 м.

Спад по графику на рисунке 4 происходит на первом этапе до $D_{\max }=46,5$ см. на втором этапе в интервале $D_{\max }=46,5-52$ см происходит стрессовое возбуждение популяции, которая за счет симбиотического взаимодействия (популяционного эффекта) сосен повышает высоту от 17 до 26 м. Эта тенденция сохраняется до толщины 70 см и продолжается дальше. Но с максимального диаметра ствола 52 см быстро начинаются волновые возмущения высоты, и с какого-то диаметра начинается климакс сосен. Но именно эти сильные колебательные воздействия возбуждают проростки семян к росту.

Приведенных в таблицах 5 и 6 закономерностей недостаточно, чтобы составить математическую модель поведения сосняка по дендрометрическим рядам. Поэтому нужно вернуться к таблице 3. Для практического применения нужно исключить расчетные факторы $D^{*}$ и $H^{*}$, а также элиминировать средние значения $\bar{D}$ и $\bar{H}$ (табл. 7).

Таблица 7

Усеченная матрица сильных связей с колебаниями

\begin{tabular}{|l|c|c|c|c|c|c|c|}
\hline \multirow{2}{*}{$\begin{array}{l}\text { Влияющие } \\
\text { факторы } x\end{array}$} & $N$ & $D_{\min }$ & $D_{\max }$ & $\Delta D$ & $H_{\min }$ & $H_{\max }$ & $\Delta H$ \\
\hline Число $N$ & & 0,7540 & 0,7940 & 0,8748 & & 0,7800 & \\
\hline Диаметр $D_{\min }$ & & & & 0,8551 & 0,9345 & 0,8974 & 0,9787 \\
\hline Диаметр $D_{\max }$ & 0,9619 & 0,8274 & & 0,9397 & 0,7727 & 0,7938 & 0,8198 \\
\hline Размах $\Delta D$ & 0,9192 & 0,9173 & 0,9688 & & 0,9080 & 0,9181 & 0,8940 \\
\hline Высота $H_{\min }$ & 0,8746 & 0,9652 & 0,9048 & 0,9277 & & 0,9609 & 0,9829 \\
\hline Высота $H_{\max }$ & 0,7546 & 0,9294 & 0,8689 & 0,9273 & 0,9695 & & 0,9613 \\
\hline Размах $\Delta H$ & 0,9502 & 0,9857 & 0,9102 & 0,9346 & $\mathbf{0 , 9 9 3 7}$ & 0,9875 & \\
\hline
\end{tabular}

Из 38 четырехчленных формул таблицы 7 можно составить множество комплексов математических моделей с разными входами (влияющие переменные) и выходами (показатели). При этом формула $H_{\min }=f(\Delta H)$ с параметрами из таблицы 6 имеет максимальную адекватность по коэффициенту корреляции 0,9937 (рис. 3).

По оригинальным биотехническим закономерностям, к которым относится функция $H_{\min }=f(\Delta H)$ одного из свойств поведения сосняка, необходимо 
провести эвристический синтез содержательных объяснений. В итоге появляется возможность обратной эвристической идентификации выявленных, но до сих пор неизвестных лесной науке, закономерностей. А такой эвристический синтез даст не только множество научно-технических идей и технических решений на уровне изобретений, но и позволит активно развивать и теорию лесной фитоценологии. Поэтому действительно образуется цикличность в теории и практике и биогеоценологии.

Заключение. Наши исследования показали, что в России лесная таксация, как совокупность количественных методов измерения свойств растущих деревьев и их сообществ, незаслуженно предано забвению из-за увлечения кубатурой древесины ствола для обслуживания хозяйственного потребления надземной части срубленных деревьев. Нами доказана возможность реанимации многочисленных первичных данных таксации модельных деревьев на примере полного анализа ствола ангарских сосен, проведенных коллективом под руководством проф. П.М. Верхунова.

Главное - это отбросить методы обработки массового статистического материала по теории среднего дерева, публиковать первичные данные измерений известных в прошлом лесных таксаторов, а затем по нашей методологии идентификации продолжить выявление закономерностей.

Это позволит в ближайшем будущем перейти на принципиально новые методы и способы (на уровне изобретений) измерения учетных деревьев в растущем состоянии и значительно расширить методологию лесной фитоценологии и биогеоценологии.

\section{СПИСОК ЛИТЕРАТУРЫ} $64 \mathrm{c}$.

1. Бёрни Дэвид. Деревья: факты, открытия, находки. М.: «Махаон», 2010.

2. Кокс Брайан. Чудеса Вселенной. М.: Эксмо, 2012. 256 с.

3. Мазуркин П.М. Геостатистика сосны // Леса России и хозяйство в них. 2009. № 3. C. 48-54.

4. Мазуркин П.М. Геоэкология: Закономерности современного естествознания. Йошкар-Ола: МарГТУ, 2006. 336 с.

5. Мазуркин П.М. Распределение фитомассы сосняка по пробным площадям // Леса России и хозяйство в них. 2009. № 3. С.22-31.

6. Мазуркин П.М. Структурно-функциональные параметры дендрорядов разновозрастного сосняка Сибири по кривым высот // Матер. 5-й научно-практ. internet-конф. «Междисциплинарные исследования в области математического моделирования и информатики» 27-28 января 2015 г. Ульяновск: SIMJET, 2015. C. 103-112.

7. Мазуркин П.М. Факторный анализ таксационных показателей // Лесное хозяйство. 2010. № 1. С. 39-40.

8. Мазуркин П.М. Факторный анализ таксационных показателей разновозрастного сосняка Сибири // Успехи современного естествознания. 2009. № 12. C. 41-48. 
9. Мазуркин П.М., Бедертдинов Э.Н., Русинова Н.В. Оценка компонентного неравновесия древостоя по кривым высот и диаметров растущих деревьев // Успехи современного естествознания. 2009. № 8. С. 23-32.

10. Мазуркин П.М., Варсегова Л.Ю. Ультразвуковое испытание древесины растущего дерева на радиальных кернах // Деревообр. пром-сть. 2010. № 3. C. 29-30.

11. Мазуркин П.М., Димитриев А.В. Сосняки заповедника «Присурский»: математический анализ параметров кварталов и выделов леса // Научные труды ГПЗ «Присурский». Т. 26. Чебоксары-Атрат: КЛИО, 2011. 104 с.

12. Мазуркин П.М., Долгих М.В. Компонентное равновесие и устойчивость древостоя. Йошкар-Ола: МарГТУ, 2011. 164 с.

13. Мазуркин П.М., Марушева В.Э. Факторный анализ параметров деревьев по контуру лесной поляны // Сб. статей научн. практ. конф. «Проблемы экологии и лесопользования в современных условиях». Йошкр-Ола: МарГТУ, 2010. C.47-52.

14. Мазуркин П.М., Михайлова С.И. Биотехническая оценка пойменного луга. М.: Изд-во «Академия естествознания», 2009. 279 с.

15. Мазуркин П.М., Михайлова С.И. Распределение фитомассы травы и деревьев в лесном фитоценозе // Современ. проблемы науки и образования. 2009. № 4. С.26-37.

16. Мазуркин П.М., Михайлова С.И., Автономов А.Н. Метод анализа территориального экологического неравновесия // Успехи современного естествознания. 2008. № 9. С.81-85.

17. Мазуркин П.М., Петренко А.О. Биоиндикация веточками и иголками ели. Йошкар-Ола: МарГТУ, 2011. 194 с.

18. Мазуркин П.М., Попова А.О. Закономерности распределения длины хвоинок на веточке ели // Международный журнал прикладных и фундаментальных исследований. 2009. № 3. С.18-24.

19. Мазуркин П.М., Попова А.О. Закономерность распределения мутовок ели // Лесной журнал. 2009. № 5. С.16-25.

20. Мазуркин П.М., Степкина Е.А. Экологическое равновесие древостоя. М.: Изд-во «Академия естествознания», 2009. 240 с.

\section{FACTOR ANALYSIS OSCILLATORY DISTURBANCES DENDRO-SERIES MULTI-AGE PINE FORESTS OF SIBERIA ON A CURVE HEIGHTS (C) 2015}

P.M. Mazurkin, Doctor of Technical Sciences, Professor, Academician of the Russian Academy of Natural Sciences and the Russian Academy of Natural Sciences, Member of the European Academy of Natural Sciences, Volga State Technological University (Yoshkar-Ola), Russia, kaf_po@mail.ru 